\title{
TWENTY-EIGHT YEARS OF EXCELLENCE
}

As GSK's flagship dental event, Talking Points in Dentistry, celebrated its twenty-eighth year of excellence in learning, the lecture series attracted over 3,000 dental professionals to ten venues across the UK.

This year saw a new format for the series, which combined a topical lecture with a follow-up panel debate session, allowing the audience to have their say. The panel was locally sourced, allowing a regional input to the events from all

\section{ONLINE APPOINTMENT BOOKING}

Need to fill your diary white space? Looking to find new patients? If these questions sound familiar then you should join Toothpick.

A smart and secure online solution suitable for both NHS and private practices, Toothpick offers instant appointment visibility to thousands of potential new patients, enabling them to find your practice and book a visit at the click of a button, 24/7, helping to fill those unsightly gaps in your appointment book, whilst you retain full control of your diary.

Toothpick offers numerous practice members of the dental practice team.

Dr Anoop Maini delivered a presentation entitled, 'Is successful dentistry more than just a beautiful smile?' The follow up panel discussion then spurred conversation around topics such as direct access and the role of the treatment co-ordinator.

If you missed out on the event, further information about the lecture and videos are available to access at www. gsk-dentalprofessionals.co.uk. advantages; it frees up reception time to focus on customer service, results in less administration and increases utilised chair time, all of which will ultimately help your practice to grow profitably and effectively.

If you're one of the 50\% of UK practices without a website, then fear not; with Toothpick no website is required as patients can click through to a fully editable practice profile. Toothpick do all the hard work so you don't have to.

Start to fill the gaps in your appointment book today and visit www.toothpick.com/get-listed, call 02081232680 or email info@toothpick.com to find out more.

\section{TASTY TOOTH PROTECTION}

GC UK's extended minimal intervention range of products includes GC Tooth Mousse. GC Tooth Mousse is waterbased, sugar-free topical cream that contains Recaldent CPP-ACP (Caesin Phosphopeptide - Amorphous Calcium Phosphate). This topical paste will provide extra protection for patients' teeth.

When CPP-ACP is applied to the tooth surfaces, it binds to biofilms, plaque, bacteria, hydroxyapatite and surrounding soft tissue localising bio-available calcium and phosphate. Saliva also enhances the effectiveness of CPP-ACP and the flavour of the tooth mousse helps to stimulate saliva flow. The longer CPP-ACP is maintained in the mouth, the more effective the result.

There is a wide range of benefits for GC Tooth Mousse.
It can be used to provide protection for teeth and to help neutralise an acidic oral environment. Additional professional applications of the mousse will be immediately following bleaching, after ultrasonic, hand scaling or root planing, after removal of orthodontic brackets, following professional tooth cleaning, after application of topical fluoride and also to provide a topical coating for patients suffering from erosion, caries and conditions arising from xerostomia. GC Tooth Mousse is available in Strawberry, Melon, Vanilla, Mint and Tutti Frutti. Contact GC UK on 01908218999 or emailinfo@ uk.gceurope. com. 